\title{
Pemodelan Matematika Perpindahan Panas Konveksi Campuran (Mixed Convection) pada Pelat Horizontal
}

\author{
Leli Deswita \\ Matematika FMIPA Universitas Riau Pekanbaru, deswital@yahoo.com \\ DOI:https://doi.org/10.15642/mantik.2017.3.2.96-100
}

\begin{abstract}
Abstrak
Penelitian ini mengkaji dan menganalisa model matematika perpindahan panas konveksi campuran (mixed convection) pada pelat horizontal. Analisa aliran perpindahan panas ini menggunakan model dalam bentuk sistem persamaan diferensial parsial nonlinear berorde dua yang berdimensi. selanjutnya persamaan ini diturunkan terlebih dahulu ke bentuk persamaan tidak berdimensi, kemudian dirobah ke bentuk sistem persamaan diferensial biasa yang nonlinear, dengan menggunakan similarity transformation. Sistem persamaan diferensial biasa yang nonlinear ini, diselesaikan dengan menggunakan metode finite-difference scheme, juga dengan program Matematika dengan Softwer matlab. Hasil yang didapat dari program ini untuk menentukan koefisien pekali geseran kulit (Skin Friction Coefficient) $f^{\prime \prime}(0)$ suhu permukaan (wall tempearture) $\theta(0)$, profil kecepatan (Velocity Profiles) $f^{\prime}(\eta)$ dan profil suhu (Temperature profiles) $\theta(\eta)$.
\end{abstract}

Kata kunci: Finite difference sheme; Konveksi campuran; Pelat horizontal

\begin{abstract}
This study examines and analyzes mathematical model of mixed convection in horizontal plate. The heat transfer uses the model of a two dimensional nonlinear partial differential equations system. Then, this equation is derived first into the dimensionless equation form, and then it is changed into system of nonlinear ordinary differential equations form using similarity transformation. This system of nonlinear ordinary differential equations is solved by using the finite-difference scheme method, also with the mathematics program with software Matlab. The results obtained form this program is to determine skin friction coefficient $f^{\prime \prime}(0)$, wall temperature $\theta(0)$ velocity profiles $f^{\prime}(\eta)$ and temperature profiles $\theta(\eta)$.
\end{abstract}

Keywords: Finite difference sheme; Mixed convection; Horizontal plate

\section{Pendahuluan}

Proses perpindahan panas secara konveksi merupakan suatu fenomena yang hanya terjadi di suatu permukaan, dimana Keadaan permukaan dan kedudukan permukaan akan mempengaruhi proses konveksi [8]. Proses perpindahan panas terjadi serentak dalam proses konveksi, disebabkan dalam proses konveksi fluida menjadi pengantar panas, sehingga besarnya kecepatan fluida yang mempengaruhi banyaknya panas yang disebarkan [14]. Perbedaan suhu diantara fluida dengan persekitaran telah menyebabkan proses konveksi terjadi [1]. Pemanasan akan menyebabkan fluida menjadi kurang padat 
(dense) dan bergerak ke atas, manakala yang lebih padat bergerak ke bawah. Proses ini akan berakhir apabila kestabilan panas tercapai.

Konsep dasar utama yang harus dipahami dalam penelitian yang akan dilakukan ini adalah masalah Konsep seperti yang telah dikembangkan oleh [3] dalam penelitian tentang solusi kesamaan untuk aliran syarat batas konveksi campuran pada pelat horizontal permeable (similarity solution for mixed convection of boundary laminer flow on permeable horizontal plate). Begitu juga dengan penelitian-penelitian yang telah dilakukan oleh [5]. Dimana para peneliti menghasilkan beberapa parameter penting seperti parameter apungan, parameter mikrokutub dan bilangan Prandtl dengan dua solusi. Selanjutnya [4] dalam penelitian tentang solusi kesamaan untuk aliran syarat batas konveksi bebas pada pelat horizontal (similarity solution of free convection boundary layer flow on a horizontal plate with variable wall temperature). Penelitian tersebut adalah berupa kajian secara teori tentang pengaruh apungan terhadap masalah syarat batas (boundary condition) aliran yang disebabkan oleh pemanasan atau pendinginan (heat transfer).

Dalam penelitian selanjutnya pakar-pakar penelitian melakukan kajian tentang aliran konveksi campuran syarat batas pada baji ( permeable walls). Aliran mantap berlapis (laminar steady flow) pada permungkaan benda berbentuk baji dengan menunjukkan penggunaan secara teori syarat batas dan bilangan Prandtl. Kemudian [10] telah mengkaji konveksi campurann pada aliran fluida micropolar, parameter mikrokutub. Selanjutnya [4] telah mengkaji aliran fluida pada pelat horizontal tentang masalah konveksi bebas dan seterusnya. Deswital mengkaji masalah aliran fluida pada pelat horizontal tentang konveksi campuran (Similarity solution for mixed convection boundary layer flow over a permeable horizontal flat plate) [3]. Selain daripada masalah pembentukan lapisan batas yang diselesaikan dengan metoda finite-differenc scheme, terdapat banyak lagi peneliti-peneliti lain mengkaji menggunakan metoda ini antara lain adalah [5], [6], [7], [10], [12], [13], [15] dan [16].

Penelitian ini menganalisa aliran perpindahan panas terhadap pelat horizontal dengan menggunakan Persamaan diferensial parsial dengan syarat batas dan konveksi campuran pada pelat horizontal Hansen [9].

\section{Formulasi Matematika}

Telah dibicarakan di atas bahwa penelitian ini menggunakan sistem persamaan diferensial parsial nonlinear dengan masalah model matematika perpindahan panas konveksi campuran (mixed conection) dengan syarat batas pada pelat horizontal, adapun bentuk model matematika yang digunakan dapat di tulis sebagai berikut

$$
\begin{aligned}
& \frac{\partial \bar{u}}{\partial \bar{x}}+\frac{\partial \bar{v}}{\partial \bar{y}}=0 \\
& \bar{u} \frac{\partial \bar{u}}{\partial \bar{x}}+\bar{v} \frac{\partial \bar{u}}{\partial \bar{y}}=-\frac{1}{\rho} \frac{\partial \bar{p}}{\partial \bar{x}}+v \frac{\partial^{2} \bar{u}}{\partial \bar{y}^{2}} \\
& 0=-\frac{1}{\rho} \frac{\partial \bar{p}}{\partial \bar{y}}+\operatorname{sg} \beta\left(\bar{T}-T_{\alpha}\right) \\
& \bar{u} \frac{\partial \bar{T}}{\partial \bar{x}}+\bar{v} \frac{\partial \bar{T}}{\partial \bar{y}}=\alpha \frac{\partial^{2} \bar{T}}{\partial \bar{y}^{2}}
\end{aligned}
$$

Dengan syarat batas,

$$
\begin{aligned}
& \bar{u}=0, \quad \bar{v}=V_{w}(\bar{x}), \\
& (\partial \bar{T} / \partial \bar{y})_{y=0}=-\bar{q}_{w}(\bar{x}) / k, \text { pada } \bar{y}=0 \\
& \bar{u}=\bar{U}(\bar{x}), \bar{T}=T_{\infty}, \bar{p}=p_{\infty} \text { apabila } \bar{y} \rightarrow \infty .
\end{aligned}
$$

Didefinisikan parameter dalam bentuk sebagai berikut :

$$
\begin{gathered}
x=\bar{x} / L, \quad y=\operatorname{Re}^{1 / 2}(\bar{y} / L), \\
v=\operatorname{Re}^{1 / 2}\left(\bar{v} / U_{0}\right), \quad U(x)=\bar{U}(\bar{x}) / U_{0}, \\
V_{w}(x)=\operatorname{Re}^{1 / 2}\left(\bar{V}_{w} / U_{0}\right), p=\left(P_{\infty}-\bar{P}\right) / \rho U_{0}^{2}, \\
T=\left(\bar{T}-T_{\infty}\right)\left(k / q_{w o} L\right) \operatorname{Re}^{1 / 2}, \quad u=\bar{u} / U_{0}, \\
q_{w}(x)=\bar{q}_{w}(x) / q_{w 0} .
\end{gathered}
$$

Dengan $\operatorname{Re}=U_{0} L / v$ adalah nomor Reynolds, $q_{\text {wo }}$ merupakan characteristik heat flux , sedangkan $L$ adalah characteristik length scale dan $U_{0}$ adalah characteristik velocity. 
Substitusikan persamaan (6) ke persamaan (1)-(5) sehingga diperoleh sebagai berikut:

$$
\begin{aligned}
& \frac{\partial u}{\partial x}+\frac{\partial v}{\partial y}=0 \\
& u \frac{\partial u}{\partial x}+v \frac{\partial v}{\partial y}=-\frac{\partial p}{\partial x}+\frac{\partial^{2} u}{\partial y^{2}}, \\
& 0=-\frac{\partial p}{\partial y}+\lambda T \\
& u \frac{\partial T}{\partial x}+v \frac{\partial T}{\partial y}=\frac{1}{\operatorname{Pr}} \frac{\partial^{2} T}{\partial y^{2}} .
\end{aligned}
$$

Dengan syarat batas (6) menjadi

$$
\begin{aligned}
& u=0, v=V_{w}(x),(\partial T / \partial y)_{y=0}=-q_{w}(x) / k, \\
& \text { pada } \quad y=0 \\
& u=U(x), \quad T=0, p=0 \text { apabila } y \rightarrow \infty .
\end{aligned}
$$

Dengan $P_{r}$ adalah nomor Prandtl dan $\lambda$ adalah konstanta konveksi campuran (mixed convection) atau disebut juga parameter keapungan (buoyancy parameter), didefenisikan sebagai berikut

$$
\lambda=s \frac{G r}{R_{e}^{5 / 2}} .
$$

Dimana $\quad G r=g \beta\left(q_{w 0} L / k\right) L^{3} / v^{2}$ merupakan nomor grashof. Selanjutnya Chellappa dan Singh [2] mendefinisikan bentuk persamaan sebagai berikut:

$$
\begin{array}{ll}
\psi=\phi_{1}(x) f(\eta), & p=\phi_{2}(x) p(\eta), \\
T=\phi_{3}(x) \theta(\eta), & \eta=\phi_{4}(x) y,
\end{array}
$$

dengan $\psi$ adalah fungsi strim yang didefinisikan sebagai berikut,

$$
u=\frac{\partial \psi}{\partial y}, \quad v=-\frac{\partial \psi}{\partial x} .
$$

Persamaan (13) disubstitusikan ke persamaan (14), selanjutnya disubstitusikan kepersamaan (7)-(11) beserta persamaan (12), kemudian diperoleh persamaan diferensial biasa sebagai berikut,

$$
\begin{aligned}
& f^{\prime \prime \prime}+\frac{n+1}{2} f f^{\prime \prime}-n f^{\prime 2}-2 n P-\frac{n-1}{2} \eta P^{\prime}=0, \\
& P^{\prime}=\lambda \theta
\end{aligned}
$$

$$
\frac{1}{\operatorname{Pr}} \theta^{\prime \prime}+\frac{n+1}{2} f \theta^{\prime}-\frac{5 n-1}{2} f^{\prime} \theta=0 .
$$

Dengan syarat batas (11) dihasilkan

$$
\begin{aligned}
& f^{\prime}(0)=0, f(0)=f_{0}, \theta^{\prime}(0)=-1 \\
& f^{\prime}(\infty)=1, \theta(\infty)=0, P(\infty)=0 .
\end{aligned}
$$

\section{Hasil dan Pembahasan}

Persamaan (15)-(17) dengan syarat batas (18) diselesaikan secara numerik untuk beberapa nilai parameter $f_{0}$ (suction), nomor prantal $P_{r}$, parameter $n$ dan $\lambda$ adalah konstanta konveksi campuran atau disebut juga parameter keapungan (buoyancy parameter) dengan menggunakan matoda finite difference schem seperti yang telah dijelaskan dalam Keller [11]

Penyelesaian secara numerik telah menghasilkan pekali geseran kulit (Skin Friction Coefficient) $\quad f^{\prime \prime}(0)$, Suhu permukaan $\theta(0)$, profil kecepatan (Velocity Profiles) $f^{\prime}(\eta)$ dan profil suhu (Temperature profiles) $\theta(\eta)$. Dalam kajian ini nilai $n$ yang diteliti adalah 0.01 dan bebrapa nilai parameter $f_{0}$ (suction), nilai nomor Prandtl yang digunakan adalah $P_{r}=0,7$ (udara). Hasil yang didapati dari kajian ini dapat dilihat pada tabel 3.1, untuk beberapa nilai $f_{0}$, dengan nilai $\mathrm{n}=0,01$ dan $P_{r}=0,7$ untuk nilai kritikal parameter $\lambda_{c}$.

Perubahan pekali geseran kulit (skin friction coefficient) $f^{\prime \prime}(0)$ terhadap $\lambda$ dapat dilihat pada Gamabar 3.2 dengan beberapa nilai parameter $f_{0}$ untuk $n=0,01$ dan $P_{r}=0,7 . \quad$ Nilai-nilai parameter $f_{0}$ yang dinyatakan pada Gambar 3.2, untuk nilai $f_{0}>0$ (suction), dan $f_{0}=0$ (impermeable plate). Perubahan suhu permungkaan $\theta(0)$ tehadap $\lambda$ dapat dilihat pada Gambar 3.3. Untuk nilai $\quad n=0,01$ dan $P_{r}$ $=0,7$. Selanjutnya pada Gambar 3.2, jika nilai $f_{0}$ meningkat, didapati bahwa pekali geseran kulit (Skin Friction Coefficient) $f^{\prime \prime}(0)$ meningkat. 


\section{JURNAL MATEMATIKA "MANTIK" \\ Edisi: Oktober 2017. Vol. 03 No. 02}

Gambar 3.4 menunjukkan Profil kecepatan (velocity profiles) $f^{\prime}(\eta)$ untuk nilai $n=0,01$ nilai $P_{r}=0,7$ dan untuk beberapa nilai parameter $f_{0}$ seperti yang dinyatakan pada Gambar 3.4, untuk $f_{0}>0$ (sedutan) dan $f_{0}=0$ (impermeable plate). Garis penuh artinya cabang atas dan garis putus-putus artinya cabang bawah. Gambar teresbut menunjukkan, untuk nilai $f_{0}$ meningkat untuk cabang atas didapati profil kecepatan berkurang dan ketebalan lapisan batas semangkin berkurang.

Gambar 3.5 menunjukkan Profil suhu (Temperature profiles) $\theta(\eta)$ untuk nilai $n=0,01$ nilai $P_{r}=0,7$ dan untuk beberapa nilai parameter $f_{0}$, seperti yang dinyatakan pada Gambar 3.5, untuk $f_{0}>0$ (sedutan) dan $f_{0}=0$ (impermeable plate). Garis penuh artinya cabang atas dan garis putus-putus artinya cabang bawah. Gambar teresbut menunjukkan, untuk nilai $f_{0}$ meningkat untuk cabang atas didapati profil kecepatan berkurang dan ketebalan lapisan batas semangkin berkurang.

Tabel 3.1. Nilai $\lambda_{c}$ Untuk Beberapa Nilai $n$ dan $P_{r}=0,7$

\begin{tabular}{|c|c|c|}
\hline $\mathrm{n}$ & $f_{0}$ & $\lambda_{c}$ \\
\hline 0,01 & 0 & $-0,0020$ \\
\hline & 0,1 & $-0,0054$ \\
\hline & $0 ., 2$ & $-0,0103$ \\
\hline
\end{tabular}

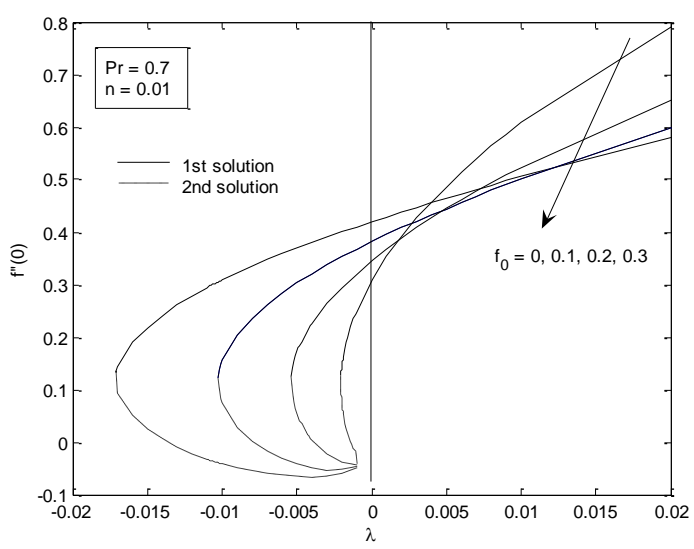

Gambar 3.2. Pekali geseran kulit (Skin Friction Coefficient) $f^{\prime \prime}(0)$ Sebagai fungsi $\lambda$ untuk beberapa nilai $f_{0}$ apabila $P_{r}=0,7$ dan $n=0,01$

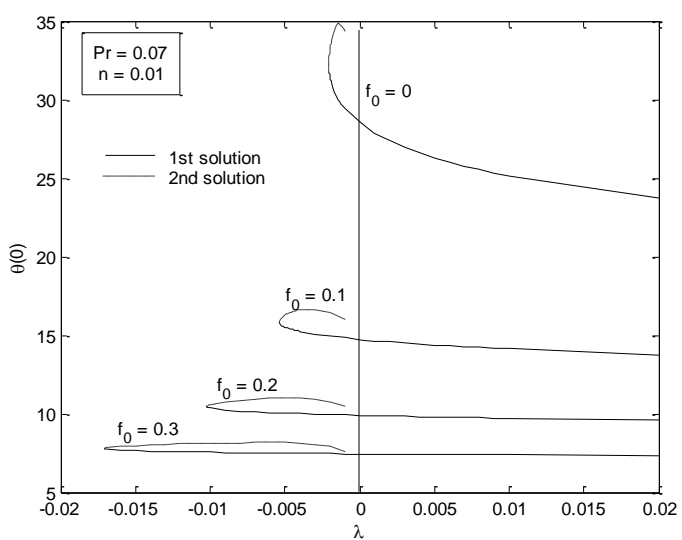

Gambar 3.3. Suhu permukaan (wall temperature) $\theta(0)$ Sebagai fungsi $\lambda$ untuk beberapa nilai $f_{0}$ apabila $P_{r}=0,7$ dan $n=0,01$.

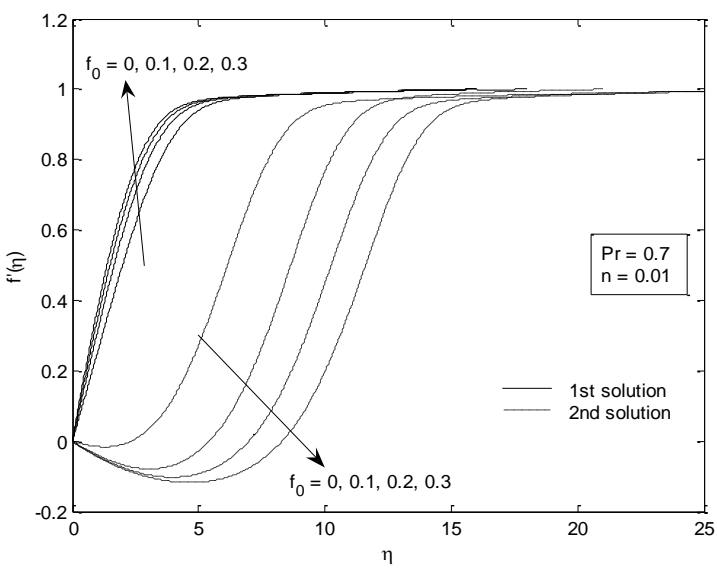

Gambar 3.4. Profil kecepatan (Velocity Profiles) $f^{\prime}(\eta)$ Untuk Beberapa Nilai $f_{0}$ Apabila

$$
p_{r}=0,7 \text { dan } n=0,01
$$

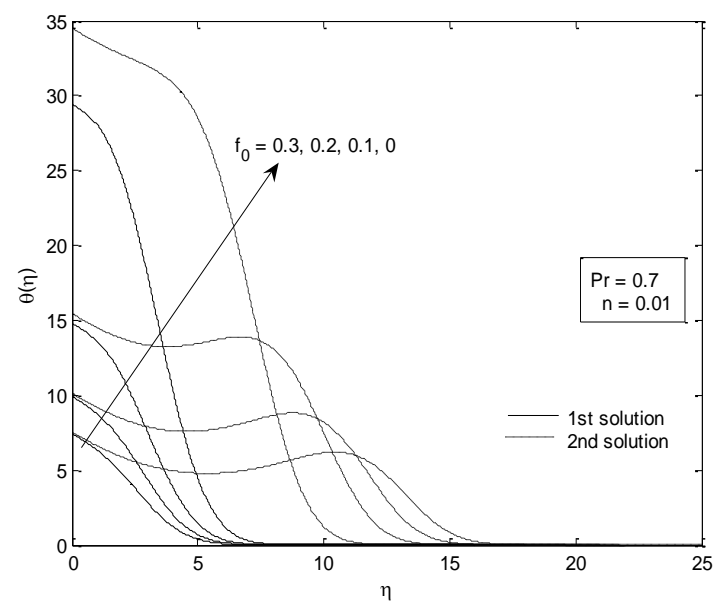

Gambar 3.5. Profil suhu (Temperature profiles) $\theta(\eta)$ Untuk Beberapa Nilai $f_{0}$ Apabila $p_{r}=0,7$ dan $\mathrm{n}=0,01$. 


\section{Kesimpulan}

Model matematika perpindahan panas konveksi campuran (mixed convection) pada pelat horizontal menggunakan model sistem persamaan diferensial parsial nonlinear berorde dua, kemudian dirobah kebentuk persamaan defenrensial biasa nonlinear dengan menggunakan metode finite-difference scheme dan program matematika softwer matlab. Hasil yang didapat dari program ini untuk menentukan koefisien pekali geseran kulit (Skin Friction Coefficient) $f^{\prime \prime}(0)$ suhu permukaan (wall tempearture) $\theta(0)$, profil kecepatan (Velocity Profiles) $f^{\prime}(\eta)$ dan profil suhu (Temperature profiles) $\theta(\eta)$

\section{Referensi}

[1] Cebeci, T. \& Brandshaw, P. 1988. Physical and Computation Aspects of Convective Heat Transfer. New York: Springer-Verlag.

[2] Chellappa, AK. P. Singh. 1989. Possible similarity formulations for laminar free convection on a semi-infinite horizontal plate, Int. J. Engng. Scei. 27: 161-167.

[3] Deswita, L., Nazar. R., Ishak. A., Ahmad. R. \& Pop. I. 2010. Similarity solution for mixed convection boundary layer flow over a permeable horizontal flat plate. Applied Mathematics and Computation 217: 2619-2630.

[4] Deswita. L., Nazar. R., Ahmad. R. Ishak. A. \& Pop. I. 2009. Similary solution of free convection boundary layer flow on a horizontal plate with variable wall tempe-rature. European Journal of Scien tific Research ISSN 1450216X Vol. 2: 188-1985.

[5] Fadzilah M. Ali, RoslindaNazar, Norihan M. Arifin \& Ioan Pop. 2014. Mixed con-vection stagnation-point flow on a vertical stretching sheetwith external magnetic field. Applied Mathematics \& Mechanics-English Edition 35(2): 155-166.

[6] Fernandez-Feria, R., Ortega-Casanova, J. 2014. A pseudospectral based method of lines for solving integro differential boundary layer equations. Application to the mixed con-vection over a heated horizontal plate, Applied Mathematics and computation. 242, pages 388396

[7] Fernandez-Feria, Del Pino, $\mathrm{C}$ and FernandeGutiérrez, A., View Affiliations. Separation in the mixed convection boundary layer radial flow over a constanta temperature horizontal plate, Physics of Fluids 26, 103603.

[8] Ghebart, B., Jaluria, Y., Mahajan, R.L, Sammakia, B. Buoyancy Induced Flows and Transport, Hemisphere, New York, 1988.

[9] Hansen, A.G. Similarity Analyses of Boundary Value Problems in Engineering, Prentice Hal Inc, New Jersey, 1964.

[10] Kartini Ahmad, RoslindaNazar \& Ioan Pop. 2012. Mixed convection in laminar film flow of a micropolar fluid. Interna-tional Communications in Heat and Mass Transfer 39(1): 36-39.

[11] Keller, H.B. 1970. A new differenc scheme for parabolic promlems. Dalam: Bramble, J Numerical Soluctions of Partical Defferen-tial Equations. New York. Achademic

[12] Rajesh Sharma, Anuar Ishak, Roslinda Nazar \& Ioan Pop. 2014. Boundary layer flow \& heat transfer over a permeable exponentially shrinking sheet in the presence of thermal radiation and partial slip. Journal of Applied Fluid Mech. 7(1): 125-134.

[13]Rashad, A. M., Chamkha, A. J, Modather. 2013. Mixed convection boundary-Layer flow past a horizontal circular cylinder embedded in a poros medium filled with ananofluid under convective boundary condition. November volume 86, Pages 380-388.

[14] Stewartson, K. 1958. on free convection from a horizontal plate, J. App. Math. Phys. (ZAMP) 276-281.

[15]Tham L, Nazar R, Pop I. 2013. Mixed convection boundary layer flow past a horizontal circular cylinder embedded in a porous Medium saturated by a nano-fluid: Brinkman model. J Porous Med 16: 445-457

[16] Tham L, Nazar R, 2014. Mixed convec-ion flow about a solid sphere embedded in a porous medium filled with a nano-fluid. Sains Malaysia 41: 1643-1649 